\title{
Surface Modification of Zinc with an Oxime for Corrosion Protection in Chloride Medium
}

\author{
Ganesha Achary, ${ }^{1}$ and Y. Arthoba Naik ${ }^{2}$ \\ ${ }^{1}$ Department of Chemistry, I. D. S. G. Government College, Chikmagalur 577 102, India \\ ${ }^{2}$ Department of P. G. Studies and Research in Chemistry, School of Chemical Sciences, Kuvempu University, \\ Shankaraghatta 577 451, India \\ Correspondence should be addressed to Y. Arthoba Naik; drarthoba@yahoo.co.in
}

Received 10 January 2012; Revised 6 June 2012; Accepted 6 June 2012

Academic Editor: Ali Nokhodchi

Copyright (C) 2013 G. Achary and Y. A. Naik. This is an open access article distributed under the Creative Commons Attribution License, which permits unrestricted use, distribution, and reproduction in any medium, provided the original work is properly cited.

The surface treatment of zinc was done with different concentrations of an oxime (2E)-2-(hydroxylamino)-1,2-diphenylethanol molecule by the immersion method. The electrochemical corrosion studies of surface-treated zinc specimens were performed in aqueous sodium chloride solution (1 M, pH 5.0) at different temperatures in order to study the corrosion mechanism. The recorded electrochemical data indicated a basic modification of the cathodic corrosion behavior of the treated zinc resulting in a decrease of the electron transfer rate. The zinc samples treated by immersion in the inhibiting organic solution presented good corrosion resistance. Using scanning electron microscopy (SEM), it was found that a protective film was formed on the surface of zinc.

\section{Introduction}

The corrosion of metals is a fundamental academic and industrial concern that has received a considerable amount of attention [1]. Zinc is the metal with numerous industrial applications and is mainly used for the corrosion protection of steels. In moist atmospheres, zinc corrodes forming white corrosion products (white rust). Chromate solutions have been applied successfully in order to protect the zinc, but recent environmental restrictions require the chromate solutions to be replaced with other reagents. Some authors have proposed soluble salts of rare earth metals for white rust prevention $[2,3]$. The influence of most of the inorganic inhibitors like chromate, phosphate, molybdate, and so forth on the corrosion of metals in $\mathrm{NaCl}$ solution has been investigated in several studies $[4,5]$. The requirements for a compound to be the efficient corrosion inhibitor are as follows: the substance should form a compact barrier film; it should chemisorb on the metal surface; it should have high adsorption energy on the metal surface; the barrier layer thus formed should increase the inner layer thickness [6]. The corrosion of metals and alloys occurs when passivity breaks down on the surface exposed to corrosive environments containing aggressive anions.

Organic reagents [7] also provide effective corrosion inhibition. Chelating agents have shown particular promise in this field [8]. These substances form stable, almost insoluble metal chelates or metal complexes, which act as protective coatings. Pokhmurs'kyi et al. studied the inhibition of corrosion by a mixture of nonchromate pigments in organic coatings on galvanized steel [9]. The number of papers dealing with chelating agents in the literature is limited. A few authors working on chelation of zinc and hence the corrosion protection of zinc [10].

In our previous paper, we have presented the effect of Schiff's bases on the surface treatment of zinc for corrosion protection [11]. In the present work, 1-hydroxy-3-methyl1-phenylhexa-3,5-dien-2-one is proposed as a new chelating reagent (Figure 1). The molecule contains electroactive $>\mathrm{C}=\mathrm{N}-$ and $>\mathrm{N}-\mathrm{OH}$ groups in order to form a complex with zinc that avoids the contact of moisture with the metal surface. 


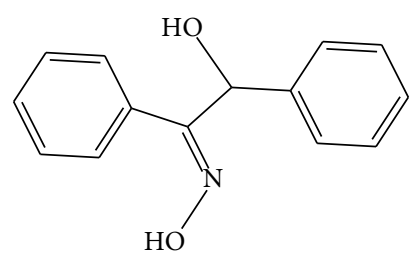

(2E)-2-(hydroxylamino)-1, 2-diphenylethanol

FIGURE 1: Structure of the compound (2E)-2-(hydroxylamino)-1,2diphenylethanol.

\section{Experimental Part}

2.1. Oxime and Test Materials. The chelating agent, an oxime is used for the surface modification of zinc, was (2E)-2(hydroxylamino)-1,2-diphenylethanol, and its structure of the oxime is shown in Figure 1.

2.2. Specimens. The pure zinc plate $(\mathrm{Cu}=0.185, \mathrm{Al}=0.006 \%$, $\mathrm{Fe}=0.004 \%, \mathrm{Mn}=0.3 \%, \mathrm{Sn}=0.003 \%, \mathrm{~Pb}=0.002 \%, \mathrm{Cd}$ $=0.002 \%$, and the rest zinc) was selected, and coupons of desired shapes with an exposed area of $1 \mathrm{~cm}^{2}$ were prepared. These samples were polished with $\mathrm{SiC}$ emery papers of different grit size (200 to 1200). These electrodes were treated with trichloroethylene vapours to remove oil and grease. The samples were rinsed with ethanol, washed with distilled water, and dried in air. The so prepared samples were used for the experiments.

2.3. Treatment Solutions and Surface Treatment of Zinc . The treatment solutions were prepared by dissolving different amount $1-7 \%$ of (2E)-2-(hydroxylamino)-1,2diphenylethanol, (1-7\%) in ethanol. The zinc specimens were immersed in these solutions for different immersion times ( 1 to 8 hours) at $298 \mathrm{~K}$. After the treatment, the zinc samples were washed with distilled water and dried in air. The treated samples were subjected to the electrochemical corrosion studies.

2.4. Corrosive Medium. The corrosion medium was $1 \mathrm{M}$ $\mathrm{NaCl}$ solutions and prepared by using the analytical grade $\mathrm{NaCl}$ and double-distilled water. All the experiments were performed in aerated solutions.

2.5. Polarization Measurements. A conventional threecompartment cell was used for the polarization measurements. The working electrode surface-treated zinc specimen of $1 \mathrm{~cm}^{2}$ exposed area, the counterelectrode platinum foil of $1 \mathrm{~cm}^{2}$ area, and reference electrode was saturated calomel as reference electrode (SCE). The SCE was connected to the main compartment via a luggin capillary to minimize the iR drop. The anodic and cathodic polarization values were measured under galvanostatic conditions using digital potentiometer (Equiptronics, model EQ-602). The potentials were scanned primarily in the cathodic direction from corrosion potential and then subsequently in the anodic direction. The electrode was held in the test solution for, few seconds, prior to the measurements, to ensure reliable corrosion, potential. Anodic and cathodic polarization potentials were recorded in the current density range of 2.0 to $500 \mu \mathrm{A} / \mathrm{cm}^{2}$. The effect of oxime concentrations in the treatment bath solutions and treatment time, on the surface modification of zinc against corrosion was tested. The polarization studies were carried out in a thermostat (model: PaaCaa, Raaga Industries, Chennai, India).

The percentage inhibition efficiency IE was calculated using the relationship

$$
\mathrm{IE} \%=\frac{i_{\text {corr }}^{o}-i_{\text {corr }}}{i_{\text {corr }}^{o}} \times 100,
$$

where $i_{\text {corr }}^{0}$ and $i_{\text {corr }}$ are the corrosion current densities for the untreated and treated zinc specimens.

2.6. Linear Polarization Method. In order to determine the polarization resistance, $R_{P}$, the potential of the working electrode $(E)$ was ramped $\pm 10 \mathrm{mV}$ in the vicinity of the corrosion potential at the scan rate of $0.1 \mathrm{mVs}^{-1}$. Polarization resistance $\left(R_{P}\right)$ was obtained from the slope of the polarization curves at low polarized potentials

$$
R_{P}=A(\text { slope of plot of } E \mathrm{v} / \mathrm{s} i),
$$

where $A$ is the surface area of the electrode.

2.7. Electrochemical Impedance Studies (EISs). Impedance spectra were recorded (AUTOLAB, Eco-Chemie) at $E_{\text {corr }}$ in the frequency range $10 \mathrm{MHz}$ to $100 \mathrm{mHz}$ with $\mathrm{AC}$ amplitude of $\pm 5 \mathrm{mV}$. Various impedance parameters like polarization resistance $\left(R_{P}\right)$, solution resistance $\left(R_{S}\right)$, and double-layer capacitance $\left(C_{\mathrm{dl}}\right)$ are determined. Nyquist plots of zinc specimens treated with the oxime are given. The study was carried out for the different concentrations of oxime in the treatment bath at different treatment time.

2.8. Scanning Electron Microscopic Studies. The surface morphology of the surface-treated zinc samples by the oxime was investigated after anodic polarization using SEM technique (model: JEOL, JSM 6400).

\section{Results and Discussion}

3.1. Electrochemical Investigations. Figure 2 presents the cathodic and anodic polarization curves in $1 \mathrm{M} \mathrm{NaCl}$ solution for the surface-treated zinc samples in 1\%,3\%, and 5\% oxime solutions at $25^{\circ} \mathrm{C}$ for $2 \mathrm{~h}$. The corrosion potential $\left(E_{\text {corr }}\right)$ was found to be $-1025 \mathrm{mV}$. There is a decrease in the current density at both anodic and cathodic regions indicating the decrease in the rate of dissolution of metal. The data in Table 1 shows the values of $E_{\text {corr }}$ shifted to negative values upon increasing the concentration of oxime in the treatment solution.

The corrosion parameters obtained from polarization curves are given in Table 1 . From Table 1, it can be seen that the protection efficiency (IE) was estimated to be $50 \%$ for 


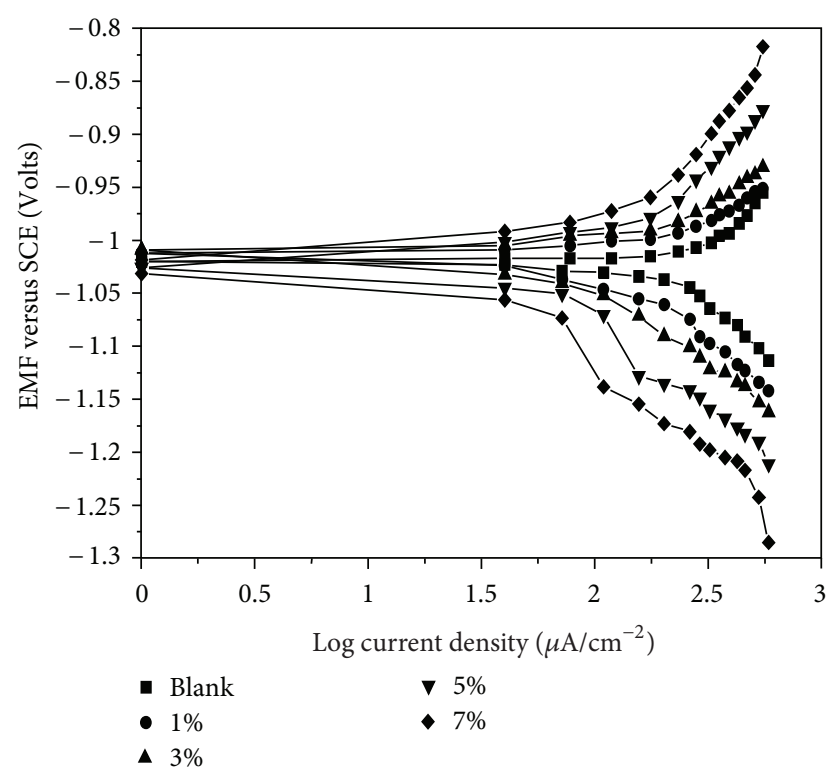

FIGURE 2: Effect of concentration of the compound on the corrosion protection efficiency of zinc in $1 \mathrm{M} \mathrm{NaCl}$.

samples treated in $1 \%$ oxime solution $\left(25^{\circ} \mathrm{C}, 2 \mathrm{~h}\right)$ and $86 \%$ for those treated in $7 \%$ solution $\left(25^{\circ} \mathrm{C}, 2 \mathrm{~h}\right)$.

The higher corrosion resistance was exhibited by the zinc samples treated in $7 \%$ oxime solutions indicating that the surface exposed to the corrosive medium is less active due to the improvement in the surface coverage by the more concentrated inhibitor. Moreover, the treatment of the zinc samples by the oxime solutions induced a basic modification of the metal cathodic behavior. When the oxime concentration increased, the cathodic and anodic curves tended towards a continuous linear shape with lower current densities. This effect could result from the presence of an organometallic protective film on the electrode surface inhibiting the formation of the porous oxide layer during the preliminary hold time at the corrosion potential and decreasing the electron transfer rate at the interface.

The action to corrosion resistance is related to the formation of a passive film on the metal surface, which was supported by SEM images of the metal surfaces. The IE values are comparable to the protection performances estimated by Felloni et al. [12] who recorded polarization curves in $0.6 \mathrm{M}$ $\mathrm{NaCl}$ aqueous medium for coatings obtained by treatment of zinc with chromate solutions, and obtained IE was $66 \%$.

The protection efficiency (IE) increased with immersion time as shown in Figure 3. Table 2 presents data for zinc samples treated at $25^{\circ} \mathrm{C}$ in $5 \%$ oxime solution for different immersion times 2-8 hrs. After eight hours, IE was stabilized and reached a maximum value of $86 \%$. The increased efficiency with treatment time gives evidence for the progressive formation of a protective film on the electrode surface.

The electrochemical behavior of the treated samples depended strongly on the temperature of the treatment bath. The surface modification of zinc was carried out using the oxime at $35^{\circ}$ to $65^{\circ} \mathrm{C}$ for 3 hours. The data of polarization

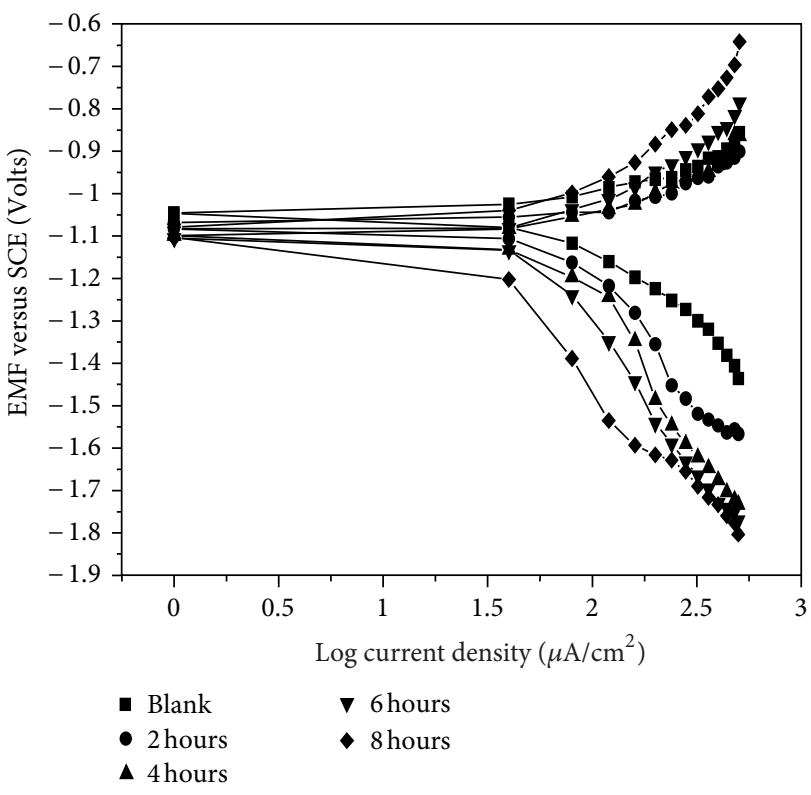

FIGURE 3: Effect of treatment time on the corrosion protection efficiency of zinc in $1 \mathrm{M} \mathrm{NaCl}$.

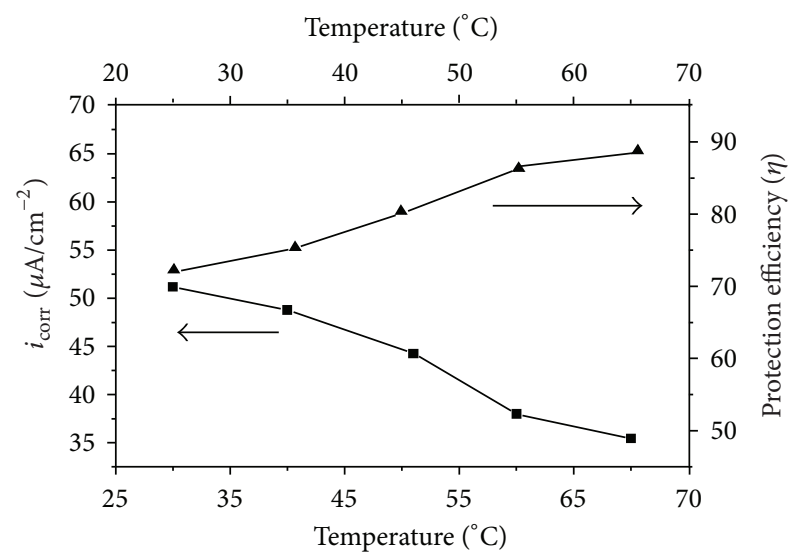

FIGURE 4: Effect of temperature on the corrosion protection efficiency of zinc in $1 \mathrm{M} \mathrm{NaCl}$.

studies for the samples treated at different temperatures are given in Table 3. Figure 4 shows that up to $55^{\circ} \mathrm{C}$, the protection efficiency was found to be increased, and above this temperature, it was stabilized to a value of $89 \%$. The effect of temperature is believed to be related to an acceleration of the chemical reaction of complex formation on the zinc surface leading to a more homogeneous protective layer.

The effect of $\mathrm{pH}$ on the corrosion protection efficiency for the zinc samples treated with $3 \%$ oxime solution $\left(25^{\circ} \mathrm{C}\right.$, $2 \mathrm{~h}$ ) was studied. Satisfactory protection was obtained only for weakly acid $\mathrm{pH}$ values around 4 . Similar behavior was observed by Leroy [13] who related the strong peak in protection offered by aqueous solutions of 2,5-dimercapto1,3,4-thiadiazole to zinc, to the incipient solubility of metal in the $4-6.5 \mathrm{pH}$ range. In more alkaline solutions, extensive oxide or hydroxide formation occasions insufficient adhesion 
TABLE 1: Electrochemical parameters and inhibition efficiency in $1 \mathrm{M} \mathrm{NaCl}$, for corrosion of surface-treated zinc at $298 \mathrm{~K}$.

\begin{tabular}{lccccc}
\hline Concentration $(\%)$ & $-E_{\text {corr }}(\mathrm{mV})$ & $-b_{c}(\mathrm{mV} / \mathrm{dec})$ & $-b_{a}(\mathrm{mV} / \mathrm{dec})$ & $i_{\text {corr }}\left(\mu \mathrm{A} / \mathrm{cm}^{2}\right)$ & 316 \\
\hline 0.0 & 1025 & 116 & 46.6 & 33.3 & 160 \\
1.0 & 1028 & 107 & 20 & 115 \\
3.0 & 1031 & 85.7 & 20 & 63 & 63 \\
5.0 & 1034 & 40 & 18 & 43 \\
7.0 & 1040 & 40 & & 85 \\
\hline
\end{tabular}

TABLE 2: Corrosion parameters for zinc treated with optimized concentration of oxime (variation of treatment time).

\begin{tabular}{lccccc}
\hline Treatment time $(\mathrm{hrs})$ & $-E_{\text {corr }}(\mathrm{mV})$ & $b_{c}(\mathrm{mV} / \mathrm{dec})$ & $b_{a}(\mathrm{mV} / \mathrm{dec})$ & $i_{\text {corr }}\left(\mu \mathrm{A} / \mathrm{cm}^{-2}\right)$ & 316 \\
\hline 0 & 1025 & 240 & 146.6 & 83.3 & 133 \\
2 & 1028 & 167 & 57 & 71 & 57 \\
4 & 1031 & 135 & 30 & 45 & 77 \\
6 & 1034 & 90 & 24 & 33 \\
8 & 1040 & 107 & & 86 \\
\hline
\end{tabular}

between the zinc and the organometallic film. In more acidic baths, the high dissolution rate of zinc hinders the formation of a protective layer on the electrode surface.

Polarization resistance values were determined from the slope of the polarization curves in the potential range $\pm 10 \mathrm{mV}$ with respect to the corrosion potential at a sweep rate of $0.1 \mathrm{mVs}^{-1}$. The $R_{P}$ values increased with increase in treatment time for the compound. The $R_{P}$ values were used to calculate the corrosion protection efficiencies $\left(\mathrm{IE}_{R_{P}} \%\right)$ using the relation

$$
\mathrm{IE}_{R_{P}} \%=\frac{R_{P}-R_{P}^{I}}{R_{P}} \times 100,
$$

where $R_{P}$ and $R_{P}^{I}$ are the polarization resistances before and after modification, respectively. The highest inhibition efficiency was $86 \%$ in $\mathrm{NaCl}$ for zinc metal treated with oxime solution of concentration $7 \%$ at $25^{\circ} \mathrm{C}$. The parallel increase in the protection efficiencies for corrosion of surfacetreated zinc in $1 \mathrm{M} \mathrm{NaCl}$ with increasing concentration of the treatment bath can be explained on the basis of inhibitor adsorption.

The corrosion behavior of surface-treated zinc samples in various concentrations of oxime solutions was investigated by EIS at $25^{\circ} \mathrm{C}$ in $1 \mathrm{M} \mathrm{NaCl}$. Various impedance parameters such as polarization resistance $\left(R_{P}\right)$, double-layer capacitance $\left(C_{\mathrm{dl}}\right)$, and $\% \mathrm{IE}_{E I S}$ for the variation of the concentration of the treatment bath are presented in Table 4 . Figure 5 shows the Nyquist plots of corresponding electrochemical impedance studies. The diagram shows imperfect semicircles, and this feature had been attributed to frequency dispersion [14]. The highest enhanced capacitive loop was obtained for a treatment bath concentration of $7 \%$. Polarization resistance is unequivocally to the corrosion current density in relatively simple corrosion systems characterized by a charge-transfercontrolled process [15]. The results show $R_{P}$ values to increase with concentration.

It should be noted from Table 4 that polarization resistance values increase with and capacitance values decrease

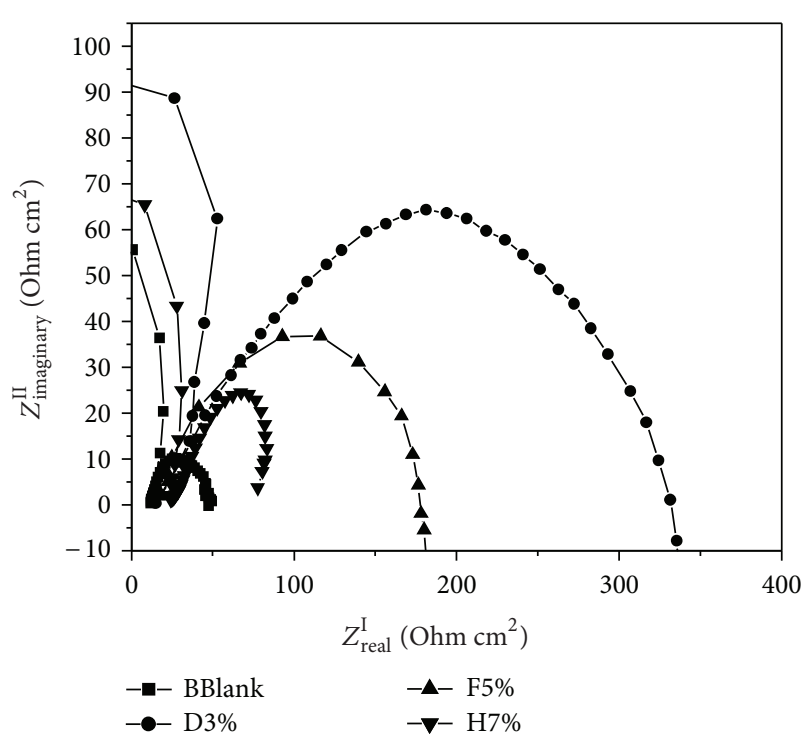

FIGURE 5: Nyquist plots of zinc in $\mathrm{NaCl}$ solution with different concentration of the oxime.

in with increase in the concentration of the compound in the treatment solution, and this indicated the formation of a surface film. The equivalent circuit of the system is a classical Randles circuit, with a parallel capacitor $(C)$ resistor $\left(R_{P}\right)$ in series with another resister $\left(R_{S}\right)$.

The corrosion inhibition property of the oxime can be attributed to the presence of heteroatoms and $\pi$ electrons on benzene ring. These factors play a vital role in the adsorption of the inhibitor and the formation of coordinate bond with metal. The adsorption of inhibitor on the zinc surface can occur by the interactions between the $\pi$ electrons of the inhibitor and the atoms of active sites of zinc surface atoms. The interaction causes the adsorption of oxime on corroding sites of zinc and prevents the dissolution reaction. As inhibitor concentration increases, it covers more and more surface area and results in the reduction of corrosion rate. 
TABLE 3: Electrochemical parameters and inhibition efficiency in $1 \mathrm{M} \mathrm{NaCl}$, for corrosion of surface-treated zinc at different temperatures.

\begin{tabular}{|c|c|c|c|c|c|}
\hline Conc. of oxime (\%) & $-E_{\text {corr }}(\mathrm{mV})$ & $b_{c}(\mathrm{mV} / \mathrm{dec})$ & $b_{a}(\mathrm{mV} / \mathrm{dec})$ & $i_{\text {corr }}\left(\mu \mathrm{A} / \mathrm{cm}^{2}\right)$ & IE (\%) \\
\hline \multicolumn{6}{|l|}{ At $35^{\circ} \mathrm{C}$} \\
\hline 0 & 1027 & 117 & 56.6 & 335 & - \\
\hline 1 & 1028 & 93.7 & 48.3 & 214 & 40 \\
\hline 3 & 1031 & 85.7 & 34.6 & 161 & 51 \\
\hline 5 & 1090 & 78.1 & 28.2 & 78 & 76 \\
\hline 7 & 1110 & 39.3 & 21.6 & 44 & 84 \\
\hline \multicolumn{6}{|l|}{ At $45^{\circ} \mathrm{C}$} \\
\hline 0 & 1030 & 95.7 & 76.6 & 334 & - \\
\hline 1 & 1040 & 85.6 & 78.3 & 223 & 35 \\
\hline 3 & 1070 & 79.7 & 64.6 & 148 & 56 \\
\hline 5 & 1090 & 62.5 & 68.2 & 68 & 78 \\
\hline 7 & 1110 & 43.3 & 51.9 & 38 & 86 \\
\hline \multicolumn{6}{|l|}{ At $55^{\circ} \mathrm{C}$} \\
\hline 0 & 1030 & 104.7 & 76.6 & 334 & - \\
\hline 1 & 1055 & 94.6 & 78.3 & 210 & 38 \\
\hline 3 & 1070 & 78.8 & 64.6 & 134 & 60 \\
\hline 5 & 1100 & 64.5 & 68.2 & 60 & 82 \\
\hline 7 & 1150 & 44.5 & 51.9 & 35 & 89 \\
\hline
\end{tabular}

TABle 4: Polarization resistance, capacitance, and inhibition efficiency for treated zinc by different concentration of the treatment bath at $298 \mathrm{~K}$.

\begin{tabular}{lccc}
\hline Conc $(\%)$ & $R_{P}\left(\Omega \mathrm{cm}^{2}\right)$ & $C_{\mathrm{dl}}\left(\mu \mathrm{F} / \mathrm{cm}^{2}\right)$ & $\mathrm{IE}_{\mathrm{EIS}}(\%)$ \\
\hline 0 & 48 & 1578 & - \\
3 & 97 & 514 & 62.2 \\
5 & 180 & 278 & 71.3 \\
7 & 350 & 201 & 79.2 \\
\hline
\end{tabular}

3.2. Scanning Electron Microscopic Studies. To investigate the performance of the protective coating, SEM study of surfacetreated zinc samples was carried out after recording the anodic polarization curve. While the untreated zinc appeared strongly corroded, in the case of treated samples, less attack of the aggressive medium was observed: the surface shows only a few pits covered with white corrosion products (Figure 6).

\section{Conclusion}

Electrochemical studies showed that zinc surface treated with (2E)-2-(hydroxylamino)-1,2-diphenylethanol has a good corrosion resistance in aqueous $\mathrm{NaCl}$ medium. The observed protection against corrosion was particularly affected by the concentration of compound, treatment time, $\mathrm{pH}$, and temperature of the treatment bath. The treatment induced a modification of the electrode behavior of zinc and decreasing the electron transfer rate during corrosion. The protection resulted from the formation of a stable organometallic film due to the interaction of the compound with the atoms of active sites of zinc surface. The surface film was formed during treatment, and the formation of white rust was reduced. This organic compounds could be used

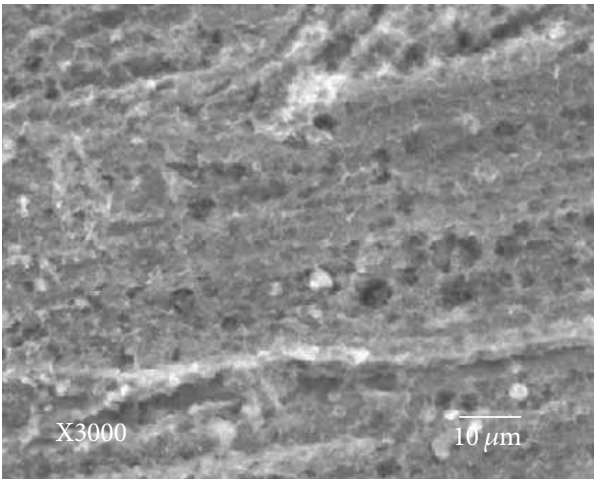

(a)

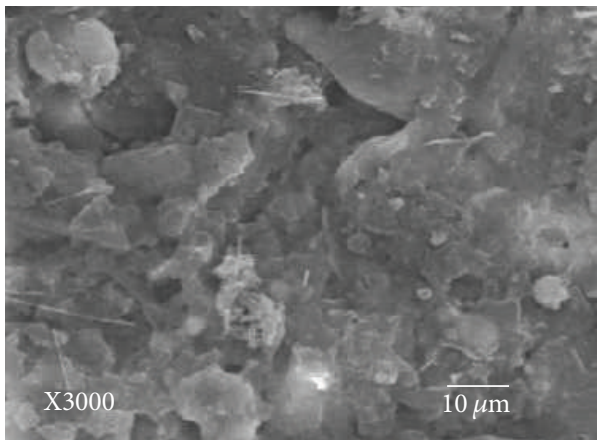

(b)

FIGURE 6: SEM images of zinc surface taken after anodic polarization:(a) untreated zinc surface, (b) zinc treated with the oxime.

as surface modifiers for zinc as nonchromate coatings for corrosion protection in aqueous $\mathrm{NaCl}$ solutions. 


\section{References}

[1] R. W. Revie and H. H. Uhlig, Corrosion and Corrosion Control, Wiley, New York, NY, USA, 4th edition, 2008.

[2] B. R. W. Hinton and L. Wilson, "The corrosion inhibition of zinc with cerous chloride," Corrosion Science, vol. 29, p. 967, 1989.

[3] M. Ihara, H. Nishihara, and K. Aramaki, "Mechanism of corrosion inhibition with bismuth compounds for ironnickel and zinc in acid solutions," Denki Kogaku, vol. 60, pp. 500-507, 1992.

[4] M. R. Laamari, A. Derja, J. Benzakour, and M. Berraho, "Calcium monofluorophosphate: a new class of corrosion inhibitors in $\mathrm{NaCl}$ medium," Journal of Electroanalytical Chemistry, vol. 569, no. 1, pp. 1-6, 2004.

[5] S. A. M. Rafaey, S. S. Abdel Rehim, F. Taha, M. B. Saleh, and R. A. Ahmed, "Inhibition of chloride localized corrosion of mild steel by PO43- CrO42-, MoO42-, and NO2- anions," Journal of Applied Surface Science, vol. 158, pp. 190-196, 2000.

[6] S. Muralidharan, K. L. N. Phani, S. Pitchumani, S. Ravichandran, and S. V. K. Iyer, "Polyamino-benzoquinone polymers: a new class of corrosion inhibitors for mild steel," Journal of the Electrochemical Society, vol. 142, no. 5, pp. 1478-1483, 1995.

[7] E. Stupnisek- Lisac and S. Podbrscek, "Non-toxic organic zinc corrosion inhibitors in hydrochloric acid," Journal of Applied Electrochemistry, vol. 24, pp. 779-784, 1994.

[8] B. Muller and I. Forster, "Corrosion inhibition of zinc pigments in aqueous alkaline media by aromatic hydroxy compounds," Corrosion, vol. 52, pp. 786-789, 1996.

[9] V. I. Pokhmurs'Kyi, I. M. Zin', and S. B. Lyon, "Inhibition of corrosion by a mixture of nonchromate pigments in organic coatings on galvanized steel," Materials Science, vol. 40, no. 3, pp. 383-390, 2004.

[10] R. Leroy, Materials Performance, vol. 19, p. 54, 1980.

[11] G. Achary, H. P. Sachin, Y. A. Naik, and T. V. Venkatesha, "Chemical treatment of zinc with a new chelating agent for corrosion protection," Bulletin of Electrochemistry, vol. 21, no. 6, pp. 241-245, 2005.

[12] L. Felloni, R. Fratesi, G. Roventi, and L. Fedrizzi, in Proceedings of the 11th International Corrosion Congress, A. I. M. Milan, Ed., vol. 2, p. 365, Florence, Italy, April 1990.

[13] R. L. Leroy, "Chelate inhibitors for zinc and galvanized products," Corrosion, vol. 34, no. 3, pp. 98-109, 1978.

[14] F. Mansfeld, M. W. Kending, and S. Tsai, "Recording and analysis of ac impedance data for corrosion studies," Corrosion, vol. 37, pp. 301-307, 1981.

[15] M. Y. Vagin, S. A. Trashin, and A. A. Karyakin, "Corrosion protection of steel by electropolymerized lignins," Electrochemistry Communications, vol. 8, no. 1, pp. 60-64, 2006. 

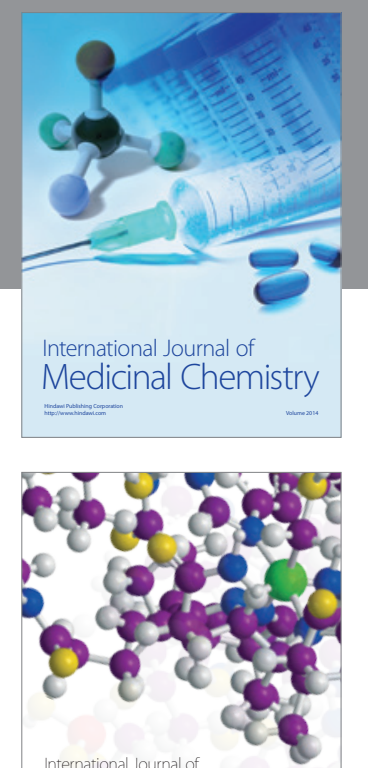

\section{Carbohydrate} Chemistry

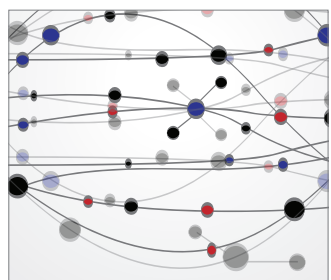

The Scientific World Journal
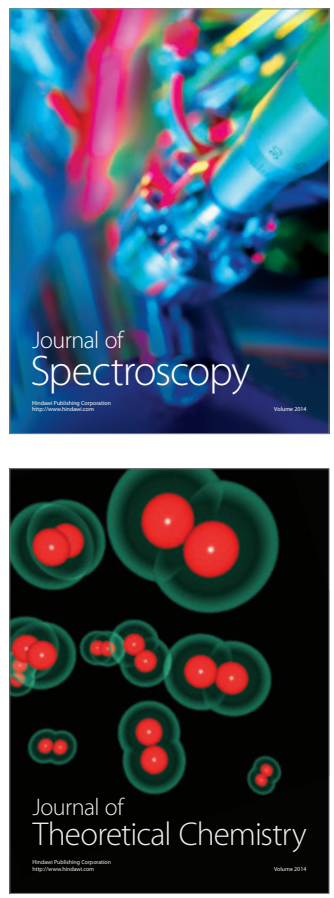
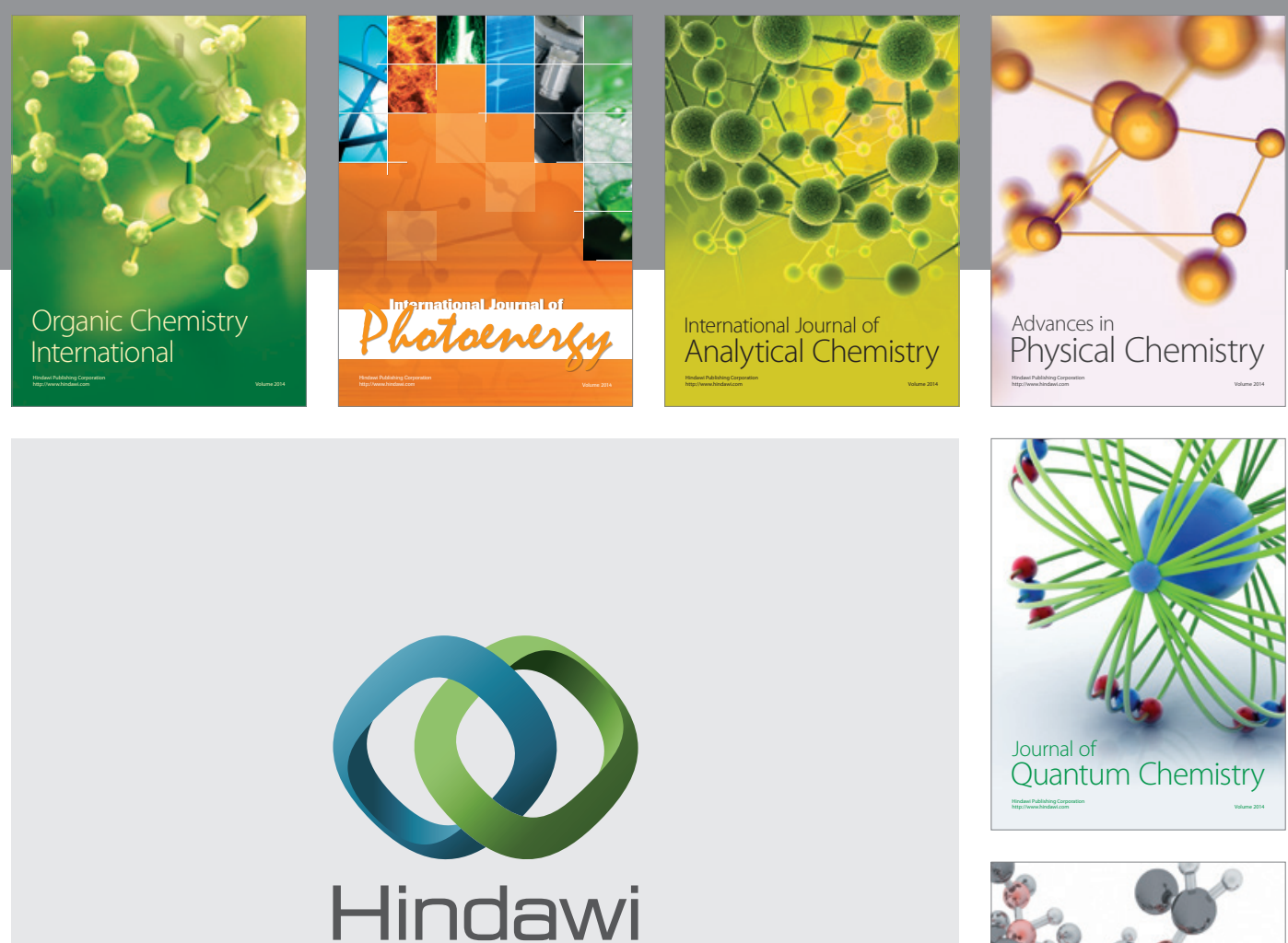

Submit your manuscripts at

http://www.hindawi.com

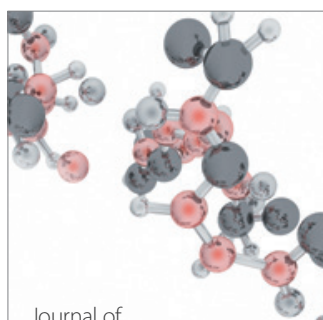

Analytical Methods

in Chemistry

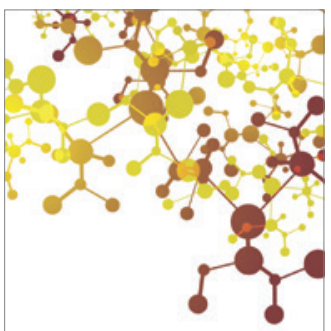

Journal of

Applied Chemistry

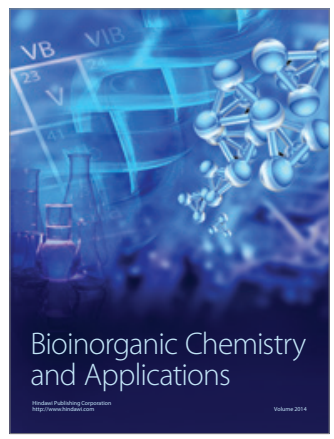

Inorganic Chemistry
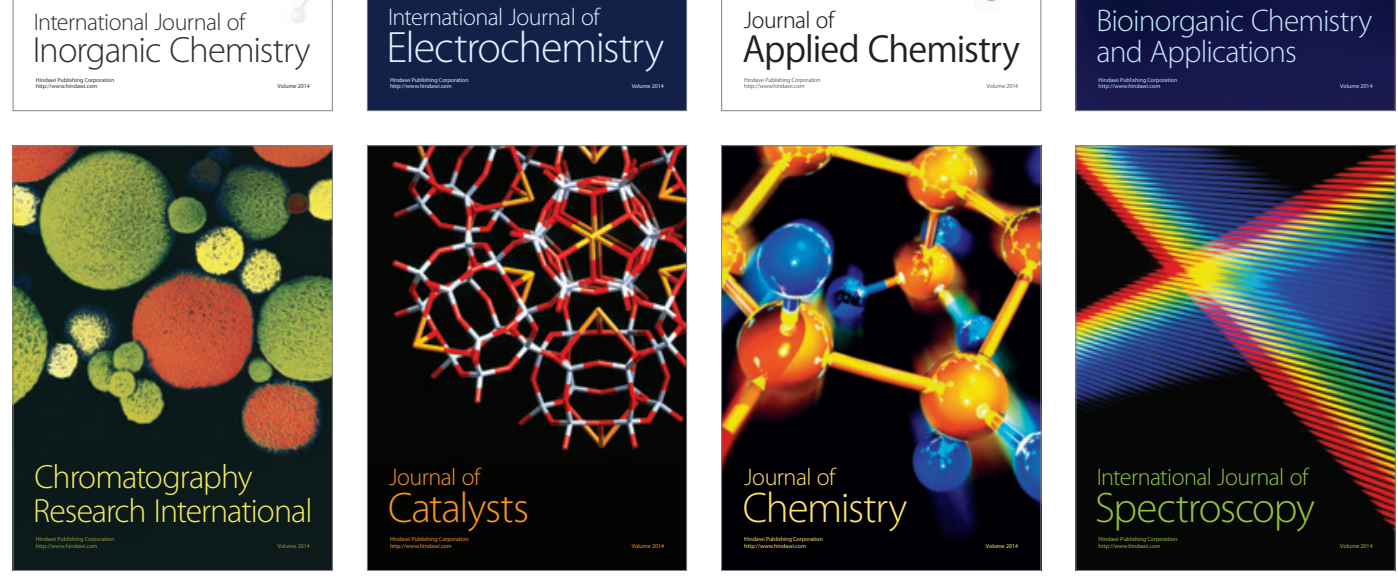